\title{
RISK-ASSESSMENT PROCEDURES AND ESTABLISHING THE SIZE OF SAMPLES FOR AUDITING FINANCIAL STATEMENTS
}

\author{
Botez Daniel \\ “Vasile Alecsandri” University of Bacău \\ daniel63331@yahoo.com
}

\begin{abstract}
In auditing financial statements, the procedures for the assessment of the risks and the calculation of the materiality differ from an auditor to another, by audit cabinet policy or advice professional bodies. All, however, have the reference International Audit Standards ISA 315 "Identifying and assessing the risks of material misstatement through understanding the entity and its environment" and ISA 320 "Materiality in planning and performing an audit". On the basis of specific practices auditors in Romania, the article shows some laborious and examples of these aspects. Such considerations are presented evaluation of the general inherent risk, a specific inherent risk, the risk of control and the calculation of the materiality.
\end{abstract}

\section{Keywords}

audit of financial statements; inherent risk; materiality

\section{JEL Classification}

M42

\section{Introduction}

Professional standards in the field statutory audits provide a series of procedures that auditors they put a few challenges with a professional. One of them, the matter shall be referred to the procedure for determining the size of samples. So, in order to determine sample size, he/she must go through a few steps:

1. Assessment of the general inherent risk

2. Assessment of the specific inherent risk

3. Calculation of materiality

4. Assessment of the risk of control

5. Analytical Review preliminary

6. Determining sample size

Note that these steps follows procedure by which the auditor also obtained information in the understanding entity and the environment or, in accordance with the provisions ISA 315 "Identifying and assessing the risks of material misstatement through understanding the entity and its environment”. This information serves as the basis of the identification and assessment of risks of significant misstatement (inherent risk and the risk of control).

\section{Assessment of the general inherent risk}

Inherent risk assessment resulting from general information relating to management and accounting environment, nature of the business entity and significant matters concerning the auditing. On the basis of concrete aspects that form the basis of the 
assessment, inherent risk is assessed on a scale from 1 to 5 , from very low to very high.

For the study we have done the assessment of the risk inherent in general on the basis of information obtained from two customers of audit, A and B, with a relatively similar situation. Thus, for both customers do not there are aspects that will lead to assessment of a very high risk. High risk is given by the situation in which the management contains shareholders. It is a common situation, in which the shareholder/shareholders are at the same time and managers, which is not necessarily indicative of a high risk. Other aspects need not entail the assessment of a high risk.

Financial position and liquidity falling within limits considered normal. The management should be considered integrate and have experience in the field of activity. In the accounts working competent personnel, there are no delays in reporting and the entity does not have a complex structure or a huge size.

Operating activity has a relatively linear character, which is based on an activity of production with continuous character. Previous audits have not revealed significant negative aspects, and their views have been without reservation. In this situation it may be observed that the evaluation lead us to a low level of risk, and by inducing a degree of additional precautions our conclusion is that it is a general risk inherent in MEDIUM, for both wireless clients.

\section{Assessment of the specific inherent risk}

The assessment of specific inherent risk shall be based on the information collected in phase in the knowledge of the consumer and documented properly in the file task. ISA 315 specifies that the identification and assessment of risks of significant misstatement shall be carried out at the level statements for the classes of transactions, balances of the accounts and presentations. Understanding customer's business experience and auditor plays a crucial role.

To assess this risk, we suggest that after identifying significant areas, to their attach risk inherent in specific resulted from the existing rules in professional, which involves the answer to six questions:

1. Subject system errors/system inadequate/manual system

2. Accounting for this area worse professional training

3. Complex operations

4. Risk of loss/misuse/fraud

5. Many professional judgment/calculations

6. Unusual Operations

We can draw up following matrix, according to receive six affirmative answers to these questions, on the basis of which to determine the level of specific inherent risk:

\begin{tabular}{|l|l|l|l|l|l|}
\hline 1,2 & Very low & Low & & & \\
\hline 3,4 & & Low & Medium & High & \\
\hline 5,6 & & & Medium & High & Very high \\
\hline
\end{tabular}

The auditors are already familiar with the array of reference for establishing the risk inherent in factor, referred to in section B7 of the guide for an quality audit: 


\begin{tabular}{|c|c|c|c|c|c|}
\hline Inherent & $\begin{array}{c}\text { Very } \\
\text { low } \\
1\end{array}$ & $\begin{array}{c}\text { Low } \\
2\end{array}$ & $\begin{array}{c}\text { Medium } \\
3\end{array}$ & $\begin{array}{c}\text { High } \\
4\end{array}$ & $\begin{array}{c}\text { Very } \\
\text { high } \\
5\end{array}$ \\
\hline Specific & & & & & \\
\hline Very low & 5 & 4 & 3 & 2 & 1 \\
\hline Low & 4 & 3,25 & 2,5 & 1,75 & 1 \\
\hline Medium & 3 & 2,5 & 1,75 & 1,5 & 1 \\
\hline High & 2 & 1,75 & 1,5 & 1,25 & 1 \\
\hline Very high & 1 & 1 & 1 & 1 & 1 \\
\hline
\end{tabular}

For our study we have kept customers and suppliers of the customer A and finished products and suppliers of the customer B. For customers of A, we've set a specific inherent risk MEDIUM, resulting in a risk inherent factor in 1.75 , for suppliers a specific inherent risk LOW, that is a risk factor of 2.5, and for finished products B and suppliers B, specific inherent risk MEDIUM, so inherent risk factor is 1.75 .

\section{The calculation of the materiality}

The materiality shall be calculated in the following assessment of the risk inherent in the level of the latter being reference basis for auditor's reasoning. So, when the general inherent risk is higher, the materiality is lower, and vice versa.

Note: ISA 320 "Materiality in planning and performing an audit", in the form as revised applicable with effect from 15 December 2009, no provision for mandatory preliminary value distribution of the threshold of significance in relation to general balances of the accounts, classes of transactions and presentations of information.

It is possible that in some cases the value of the threshold of significance to the financial statements as a whole to be suitable for the purpose of establishing some samples which would lead to the degree of assurance required. But there are also circumstances in which the auditor must use values lower than this. ISA 320 introduce the concept of performance materiality, which makes a request for the addition of value to auditor's reasoning establishing a low level of materiality to reduce to a reasonable level likely uncorrected distortions or not detected to exceed the materiality for financial statements as a whole.

On the other hand, ISA 320 provides for entity's specific circumstances in which the auditor also may lay down and use values well below the materiality for certain classes of transactions, balances of accounts or presentations. ISA 320 shall submit, as a reference basis, particular cases where the auditor can do, no longer be compulsory for all items for the different levels of materiality for financial statements as a whole.

For case study we've set the materiality to the financial statements as a whole for the two entities of reference, from the average of between the smallest and the largest value of six reference values calculated on the basis of a model which calls up to three relevant indicators in the financial statements: $1-2 \%$ of turnover, $1-2 \%$ of assets and $5-10 \%$ of the profit. After carrying out these calculations have established the materiality to the following values:

Materiality Company A: 200.000 lei

Materiality Company B: 300.000 lei

\section{Assessment of the risk of control}

Control risk assessment is based on the information collected in respect of the system of internal control and documented in the appropriate working sheets. Under the conditions in which the auditor also considers that the information on the state of the environment of the control and monitoring mode to carry out the inspections are 
appropriate and shall be based on the findings internal control, implement tests to confirm proper operation of the machine.

Assessment of this risk involves, therefore, in addition to reasonable character organization discovery system of internal control, the existence and application of procedures for testing and effectiveness of controls. As a general rule, these procedures shall be developed by each cabinet of audit. It is a very important aspect because on the basis of the result testing internal controls the auditor also determines in which may be based on the findings internal control on a scale of 1 to 5 , and attach the factor 1 a high risk and the factor 5 a low risk. For the purpose of this study, we can establish that he/she has not considered it appropriate to rely on internal control findings and, as a result, assessed control risk at the level of $100 \%$, following the factor of 1 .

\section{Preliminary analytical review}

Analytical procedures claim our understanding of auditor of the entity and the environment or helping him in adequate evaluation of the risk of serious distortions. As a matter of principle, they shall consist of comparisons between the various financial information concerning the entity as well as information for precedent periods such as indicators of liquidity, solvency, performance, or the main categories of expenditure, and the identification of significant variations which require specific attention. From the point of view of the calculation of sample size, pre-analytical revision used in fixing by auditor of a factor of relevance on a scale of 1 to 3 , the factor 1 representing the situation that analytical review is not granted no relevance, while the factor 3 assumes that the review did not reveal unusual items.

Sample size calculation has as reference table for the calculation of the guide on an audit of quality, used in professional practice in Romania, to section B7:

\begin{tabular}{|l|c|c|c|c|c|c|}
\hline \multicolumn{1}{|c|}{ Element } & Population & Materiality & $\begin{array}{c}\text { Inherent } \\
\text { risk } \\
\text { factor }\end{array}$ & $\begin{array}{c}\text { Control } \\
\text { risk } \\
\text { factor }\end{array}$ & $\begin{array}{c}\text { Analytical } \\
\text { Review } \\
\text { factor }\end{array}$ & $\begin{array}{c}\text { Sample } \\
\text { minimum } \\
\text { level }\end{array}$ \\
\hline Customers A & 3.422 .000 & 200.000 & 1,75 & 1 & 2 & 5 \\
\hline Suppliers A & 1.201 .500 & 200.000 & 2,5 & 1 & 2 & 1 \\
\hline $\begin{array}{l}\text { Finished } \\
\text { products B }\end{array}$ & 2.069 .063 & 300.000 & 1,75 & 1 & 3 & 1 \\
\hline Suppliers B & 1.849 .625 & 300.000 & 1,75 & 1 & 3 & 1 \\
\hline
\end{tabular}

By means of the procedure for the establishment of the samples levels have been laid down their minimum. To validate reasoning's that we made, we will present procedures by which we audited those structures. Analysis of structures taken as example emphasizes the following:

Customers A: The balance of 3.422.000 lei is composed of 90 clients, of which 6 have a value of the balance over the value of the materiality. The sum of them is of 2.316.675 lei, which represents $68 \%$ of the total. We can assume the sample results are satisfactory.

Suppliers A: The balance of 1.201 .500 lei is composed of 114 suppliers, of which only one exceeds the value of the materiality, with a balance of 546.484 lei, representing $45 \%$. In this situation, in order to obtain an adequate level of insurance for suppliers, the auditor must extend sample size to 3 components, each with a value over 150.000 lei, which have a value 858.053 lei, representing $71 \%$ of the total value of the balance, a comfortable situation. 
ISA 320 provides that the performance materiality may be represented by one or more of the values. If the auditor would be determined by planning a threshold of functional significance of 150.000 lei for similar items suppliers, sample size would have been different.

Finished products B: The balance of 2.069.063 lei is composed of 51 items of which 2 are located above the materiality, with a cumulative value of the balances of 830.820 lei, representing $40 \%$ of the total. To obtain the assurance required, the auditor also lays down a sample of 5 items with a value of 1.413 .399 lei, representing $68 \%$ of the total balance, which would have resulted in the planning stage if he had established a performance materiality of 100.000 lei.

Suppliers B: The balance of 1.849 .625 lei is composed of 208 suppliers, no balance individually does not exceed the value of the materiality. If the auditor would be established a smaller performance materiality, 100.000 lei, then that's it is located 4 suppliers with a cumulative value of the balances of 599.046 lei, representing only $32 \%$. In this situation, the auditor would have had to establish a performance materiality less than, 50.000 lei, and then in the sample shall enter 10 items with a cumulative value of 946.555 lei, representing 51\%, which correlated with the assessed risk can be considered satisfactory.

As a result of these successions, the establishment of performance materiality at the planning stage would have resulted in a minimum size of the samples closest to the requirements for obtaining the degree of assurance required, such as:

\begin{tabular}{|l|c|c|c|c|c|c|}
\hline \multicolumn{1}{|c|}{ Element } & Population & Materiality & $\begin{array}{c}\text { Inherent } \\
\text { risk } \\
\text { factor }\end{array}$ & $\begin{array}{c}\text { Control } \\
\text { risk } \\
\text { factor }\end{array}$ & $\begin{array}{c}\text { Analytical } \\
\text { Review } \\
\text { factor }\end{array}$ & $\begin{array}{c}\text { Sample } \\
\text { minimum } \\
\text { level }\end{array}$ \\
\hline Customers A & 3.422 .000 & 200.000 & 1,75 & 1 & 2 & 5 \\
\hline Suppliers A & 1.201 .500 & 150.000 & 2,5 & 1 & 2 & 2 \\
\hline Finished products B & 2.069 .063 & 100.000 & 1,75 & 1 & 3 & 5 \\
\hline Suppliers B & 1.849 .625 & 50.000 & 1,75 & 1 & 3 & 7 \\
\hline
\end{tabular}

On the other hand, a rigorous approach to risk assessment and analytical procedures, through the inclusion of some degrees of precaution raised, may change the value factors, with significant impact over the size of samples.

\section{Conclusions}

Determining sample size represents an adjustment procedure again based on auditor's reasoning, which brings together all the information and assessments have been observed with respect to entity.

In the first place, assessment of the general inherent risk has a significant influence on thoughts on fixing of general materiality, and together with the inherent risk specific, by placing them in the matrix for the identification of the risk inherent in factor, on a scale from 1 to 5 they have a significant impact on sample size calculation.

Secondly, ISA 320 leave the responsibility and at the expense auditor's reasoning both fixing of global materiality, and use of performance materiality or set materiality for specific classes of transactions, balances of accounts or presentations. This constitutes a margin of action wide enough for auditor and allows the operator to obtain the assurance necessary.

Thirdly, the establishment of control risk factor attached on a scale of assessment from 1 to 5 , has a significant impact on sample size. It is necessary that the auditor, on the basis of tests carried out on the system of internal control and document and establish various factors for the various structures of financial statements. 
Last but not least, preliminary analytical review must have regard to the indicators and representative structures for the activity entity, as establishing a relevant factor on a scale of 1 to 3 has a significant impact over the size of samples.

\section{References}

CAFR (2014), The Guide of an Quality Audit, Bucharest.

ISA 315 "Identifying and assessing the risks of material misstatement through understanding the entity and its environment" and ISA 320 "Materiality in planning and performing an audit”, in IAASB - Handbook of International Regulations for Quality Control, Auditing, Review, Other Assurance Services and Related Services, Edition 2012, vol. I, translated and reissued the CAFR, Bucharest, 2013. 